\title{
Research on Diesel Engine Energy Saving and Emission Reduction Based on Air System and NOx Virtual Sensor Model
}

\author{
Xuejun Li, Miao Liu, Chuanchang Li \\ Shanghai University of Engineering Science, Shanghai, China \\ Email: 819015691@qq.com
}

How to cite this paper: Li, X.J., Liu, M.O. and Li, C.C. (2018) Research on Diesel Engine Energy Saving and Emission Reduction Based on Air System and NOx Virtual Sensor Model. Open Access Library Journal, 5: e4597.

https://doi.org/10.4236/oalib.1104597

Received: April 12, 2018

Accepted: May 21, 2018

Published: May 24, 2018

Copyright $\odot 2018$ by authors and Open Access Library Inc.

This work is licensed under the Creative Commons Attribution International License (CC BY 4.0). http://creativecommons.org/licenses/by/4.0/

\begin{abstract}
As of the beginning of 2017, the number of motor vehicles in our country exceeded 300 million. Motor vehicle emissions are one of the most important sources of atmospheric haze. Therefore, vehicle emissions and energy consumption have always been important research directions for emission reduction and energy saving. In this paper, IOC (intake oxygen concentration) observer and feedforward controller of EGR and VGT are designed based on diesel engine air model. NOx virtual sensor model is designed to detect NOx emission as the feedback variable of IOC observer, and achieve the purpose of accurately measuring the amount of NOx, controlling the EGR valve and the VGT blade in real time, reducing the NOx emission of various diesel engines, improving the fuel economy of the engine and reducing the source of the haze, and there is an important reality in this research and the later promotion and social significance.
\end{abstract}

\section{Subject Areas}

Mechanical Engineering

\section{Keywords}

Diesel Air System, Exhaust Gas Recirculation, Variable Geometry

Cross-Section Turbocharged, Virtual Sensor

\section{Research Background and Research Status at Home and Abroad}

Air pollution has become an increasingly serious environmental problem, restricting the rapid development of the political and economic fields in various 
countries and endangering the normal and healthy life of the people. Although there are many causes of atmospheric pollutants, automobile exhaust is undoubtedly the "repeat offender" [1]. The main emission pollutants of automobile exhaust are NOx and PM, among which the amount of NOx emitted by diesel engines accounts for about $35 \%$ of the exhaust emissions, which is harmful to the human body [2]. Due to the increasing use of diesel engines in automobiles, ships and construction machinery, and in order to cope with the environmental problems thus caused, governments of all countries have to increase their efforts to control their emissions.

Therefore, in view of the complexity of the control system mentioned above, this paper designs a control model of EGR and VGT based on the model of diesel air system, and uses the data measured by IOC observer and NOx virtual sensor to largely improve the response speed and stability of the whole control system, and solve the problem of slow response and poor stability of the complex control system so as to reduce NOx emission better.

\section{Diesel air Control System}

\subsection{Diesel Engine Air System Principle}

As shown in Figure 1, the mixture of fresh air and exhaust gas enters the cylinder through the intake manifold. The combustion in the cylinder generates a large amount of heat to drive the engine to run. The exhaust gas generated after the combustion is discharged through the exhaust manifold. Some of the exhaust gases pass through the EGR valve and the EGR cooler mixes with the fresh air to return to the intake manifold. In addition, the NOx virtual sensor can measure the amount of NOx in the exhaust gas. By combining the NOx feedback amount with the control system, the lift of the EGR valve is controlled, the EGR rate is changed, and the combustion speed is slowed down so that the pressure in the combustion chamber is formed slow down to achieve the effect of reducing NOx emissions.

However, EGR may degrade the oxygen concentration in the intake air and cause the engine power to drop. In order to increase the oxygen concentration of the intake air and increase the power of the engine, the VGT needs to be used with EGR. VGT variable cross-section turbocharger system, the exhaust gas was emitted by the engine inertial momentum to promote the turbine chamber turbine, turbine-driven coaxial impeller. Impeller compressed fresh air, through the intercooler, after the pressure into the cylinder by controlling the position of the turning vanes to change the turbine flow area, and then controlling the supercharger speed and supercharging pressure, to ensure the power of the engine, to achieve energy-saving purposes.

\subsection{Diesel Engine Control System Strategy}

Figure 2 is EGR and VGT control system control strategy diagram. The target of control is the lift of the EGR valve and the position of the VGT blade, from the 


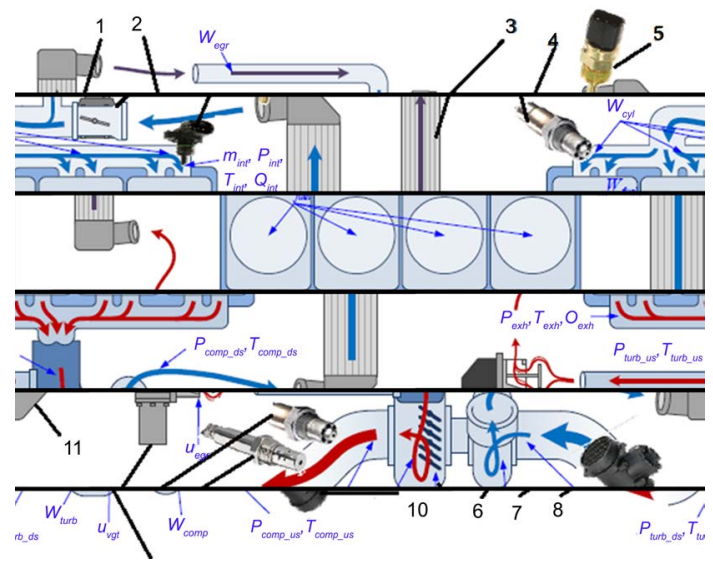

Figure 1. Air system schematic and physical status.

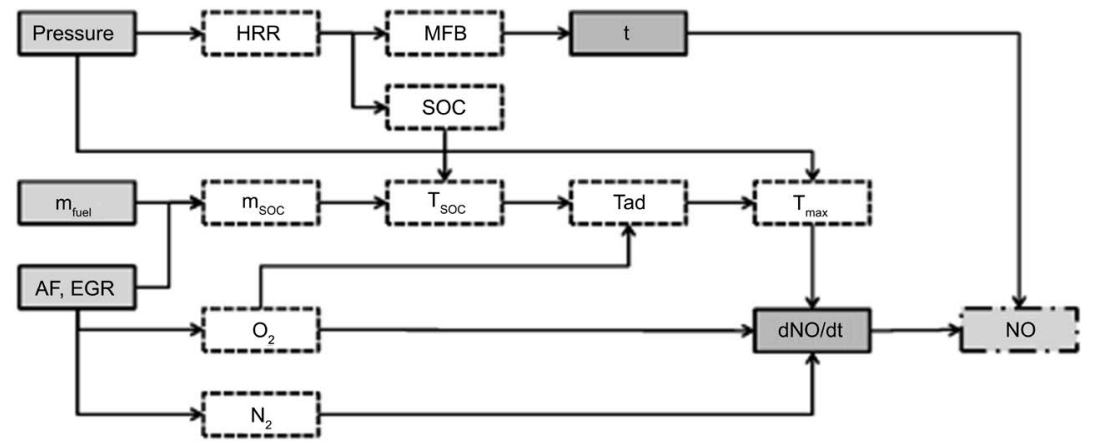

Figure 2. EGR and VGT control system control strategy diagram.

air system model and air system settings module as a feedforward controller input. At the same time, the NOx concentration measured by the IOC observer and the NOx emission measured by the NOx virtual sensor are used as the feedback values. The input quantity and the feedback quantity form a closed-loop control system, and finally the lift of the EGR valve and the position of the VGT blade are derived.

\section{Diesel Air System Modeling}

Because the physical state annotated in Diesel air system diagram cannot be directly measured. Therefore, we need to establish a model to deduce these physical states that cannot be directly measured, and provide inputs for the following IOC oxygen concentration observer and EGR, VGT feedforward controller research.

As shown in Figure 3, the diesel engine air system model is divided into the intake manifold, cylinder, EGR, exhaust manifold, VGT and other related gas models. The intake manifold gas quality and temperature are first derived from the intake manifold pressure obtained from the MAP sensor, the compressor mass flow obtained from the HFM sensor, and the engine speed. The cylinder gas mass flow obtained from the intake manifold gas mass together with the temperature of the intake manifold derives the exhaust manifold temperature 


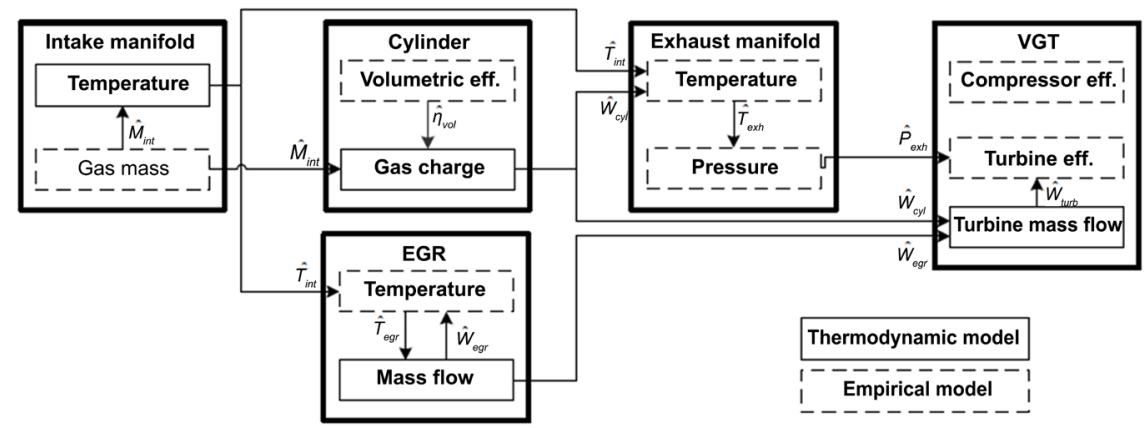

Figure 3. Diesel engine air system model frame diagram.

and pressure. Additionally, the temperature of the intake manifold derives the EGR gas temperature and the EGR gas mass flow rate. Turbine efficiency is derived from turbine mass flow and cylinder gas pressure derived from cylinder gas mass flow and EGR mass flow.

The following are several important models in a diesel air system model:

1) Intake manifold gas quality derivation model.

$$
\hat{M}_{\text {int }}=a_{00}+a_{10} P_{\text {int }}+a_{01} \frac{W_{\text {comp }}}{N_{\text {eng }}}+a_{20} P_{\text {int }}^{2}+a_{11} P_{\text {int }} \frac{W_{\text {comp }}}{N_{\text {eng }}}+a_{02}\left(\frac{W_{\text {comp }}}{N_{\text {eng }}}\right)
$$

2) Intake manifold gas temperature derivation model.

$$
\hat{T}_{\mathrm{int}}=\frac{P_{\mathrm{int}} V_{\mathrm{int}}}{\hat{M}_{\mathrm{int}} R}
$$

3) Cylinder gas mass flow derivation model.

$$
\hat{W}_{\text {cyl }}=\frac{V_{\text {disp }}}{120 V_{\text {int }}} N_{\text {eng }} \hat{M}_{\text {int }} \hat{\eta}_{\text {vol }}
$$

4) EGR mass flow derivation model.

$$
\hat{W}_{\text {egr }}=\frac{1}{\hat{T}_{\text {egr }}}\left(\frac{\dot{P}_{\text {int }} V_{\text {int }}}{R \kappa}-W_{\text {comp }} T_{\text {ic,ds }}+\hat{W}_{\text {cyl }} \hat{T}_{\text {int }}\right)
$$

5) Exhaust trachea pressure derivation model.

$$
\hat{P}_{\text {exh }}=P_{\text {turb,ds }} \cdot\left(\begin{array}{l}
d_{00}+d_{10} \frac{\hat{W}_{\text {turb }} \sqrt{\hat{T}_{\text {exh }}}}{P_{\text {turb,ds }}}+d_{01} u_{\mathrm{vgt}}+d_{20}\left(\frac{\hat{W}_{\text {turb }} \sqrt{\hat{T}_{\text {exh }}}}{P_{\text {turb,ds }}}\right)^{2} \\
+d_{11} \frac{\hat{W}_{\text {turb }} \sqrt{\hat{T}_{\text {exh }}}}{P_{\text {turb,ds }}} u_{\text {vgt }}+d_{02} u_{\mathrm{vgt}}
\end{array}\right)
$$

6) Turbine gas mass flow.

$$
\hat{W}_{\text {turb }}=\hat{W}_{\text {cyl }}+W_{\text {fuel }}-\hat{W}_{\text {egr }}
$$

\section{IOC Observer Design}

The observer estimates the oxygen concentration in the exhaust manifold using the air system model and the four known (measured or setpoint) states of the 
five physical states.

As shown in Figure 4, before designing the IOC observer, the mean oxygen concentration model was first proposed. From the physical state in Figure 4, the matrix parameter model for $\mathrm{A}$ and $\mathrm{W}$ can be obtained, and the matrix parameter model of $\mathrm{L}$ can be obtained according to the Lyapunov theorem. The three are integrated and re-integrated to obtain the oxygen concentration into the exhaust manifold. Matrix $\mathrm{W}$ gives straightforward oxygen concentration data. The matrix A is designed by Lyapunov theorem, which ensures the stability of IOC observer control. The matrix L uses the crude exhaust manifold oxygen concentration as a negative feedback as a correction value, gradually approximating the true value to obtain an accurate oxygen concentration value.

So IOC observer control model as formula (7):

$$
\begin{aligned}
{\left[\begin{array}{c}
\dot{\hat{O}}_{\text {int }} \\
\dot{\hat{O}}_{\text {exh }}
\end{array}\right] } & =A\left[\begin{array}{c}
\hat{O}_{\text {int }} \\
\hat{O}_{\text {exh }}
\end{array}\right]+W+L(y-\hat{y}) \\
& =\left[\begin{array}{ll}
a_{11} & a_{12} \\
a_{21} & a_{22}
\end{array}\right]\left[\begin{array}{l}
\hat{O}_{\text {int }} \\
\hat{O}_{\text {exh }}
\end{array}\right]+\left[\begin{array}{l}
w_{1} \\
w_{2}
\end{array}\right]+\left[\begin{array}{l}
l_{1} \\
l_{2}
\end{array}\right](y-\hat{y})
\end{aligned}
$$

\section{Feedforward Controller Design}

The feedforward controller is designed to precisely control the lift of the EGR valve and the position of the VGT blades to increase the response speed of the control system and thereby reduce NOx emissions.

\subsection{EGR Valve Lift Feedforward Control Model}

The parameters in Figure 5 are used to derive the EGR mass flow settings, EGR mass flow settings, and other parameters from the EGR valve control model to derive the EGR lift value from the intake manifold gas mass balance model.

EGR valve control model as shown in formula (8) below:

$$
u_{\mathrm{ff}, \mathrm{egr}}=\left\{j_{1}\left(\frac{X_{\mathrm{egr}}}{Y_{\mathrm{egr}}^{j_{2}}}\right)^{2}+j_{3}\left(\frac{X_{\mathrm{egr}}}{Y_{\mathrm{egr}}^{j_{2}}}\right)+j_{4}\right\}
$$

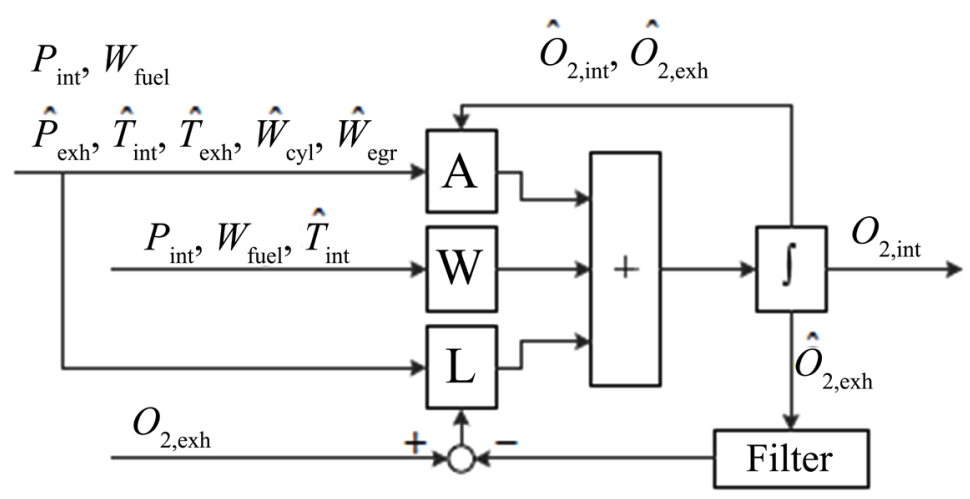

Figure 4. IOC observer control strategy. 


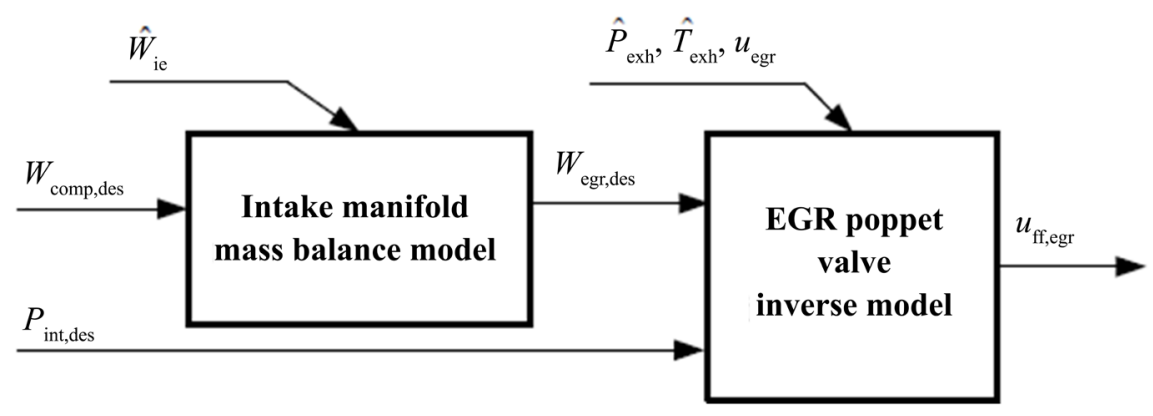

Figure 5. EGR valve control model.

\subsection{Feedforward Control Model of VGT Blade Position (Figure 6)}

Through the compressor power model, the exhaust manifold gas quality model, the turbine power model and the VGT blade model, the control model of the VGT blade position is finally deduced.

VGT blade control model as shown in (9):

$$
u_{\mathrm{ff}, \mathrm{vgr}}=\frac{1}{k_{1}}\left[\frac{1}{\left(k_{2} \cdot\left(X_{\mathrm{vgt}}\right)+k_{3}\right.} \cdot Y_{\mathrm{vgt}}-k_{4}\right]
$$

\section{NOx Virtual Sensor Modeling}

Compared with traditional sensors, NOx virtual sensors measure the amount of NOx more accurately. At the same time, the measured NOx is used in the control system's emissions feedback to better respond to the system's control.

\section{Simulation and Experimental Verification}

\section{Air System Simulation and Experimental Validation}

Figure 7 shows the comparison of the predicted NO (NOx) and measured NO (NOx) during the ECE-15 and EUDC cycles in real-time. NOx was measured by an exhaust gas analyzer (Horiba, MEXA-7100DEGR) because the fast NO analyzer needs an additional NOx converter to measure NOx. Additionally, for simultaneous measurement of $\mathrm{NO}$ and NOx, the use of two sets of equipment was needed. It is shown that the model predicts the real-time NO and NOx emissions well compared with the measurement results.

The image from Figure 7(a) is magnified from 120 - $150 \mathrm{~s}$ in Figure 8. Inaddition, the result of the simultaneous NO measurement using the exhaust gasanalyzer is also described. It is shown that the exhaust gas analyzer had a measurement delay of approximately 5 seconds compared with the fast $\mathrm{NO}$ analyzer. Additionally, it can be observed that the result of the exhaust gas analyzer is smoother. Increasing and decreasing rate is also lower than that of the fast NO analyzer. It is due to not only the difference in the response time of the analyzer itself but also the longer sampling line of the exhaust gas analyzer. However, the total amount of measured NO by the two sets of equipment agrees well with the calculation of the integral on time. 


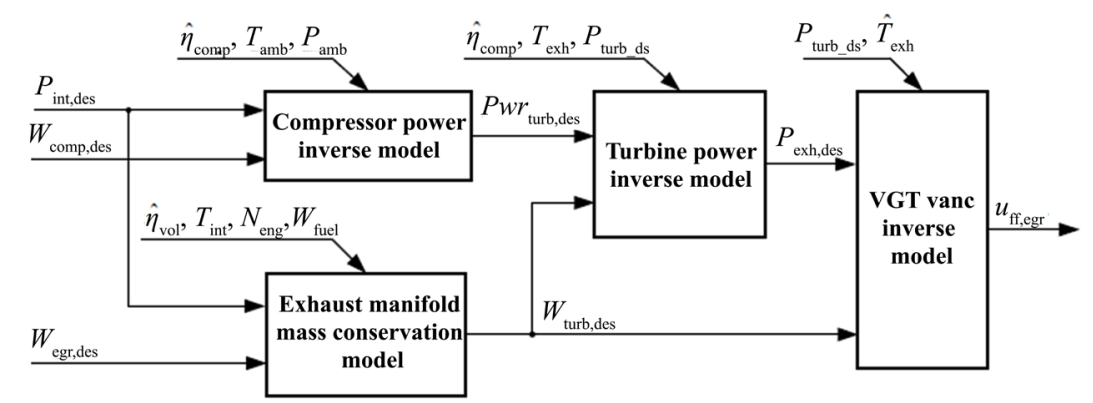

Figure 6. VGT blade feedforward control model.

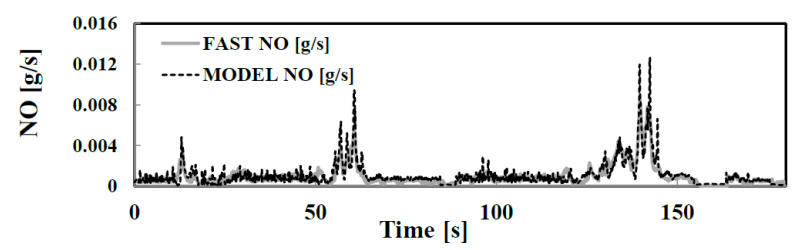

(a)

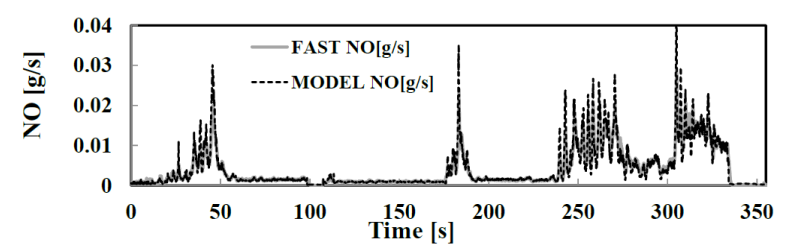

(b)

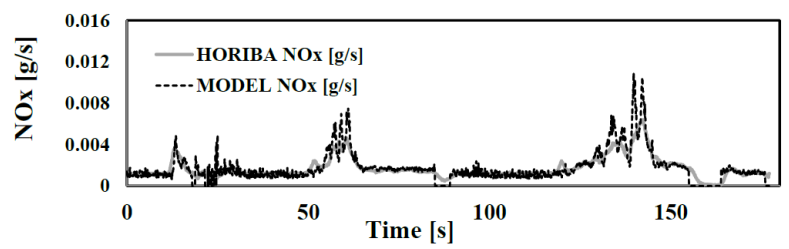

(c)

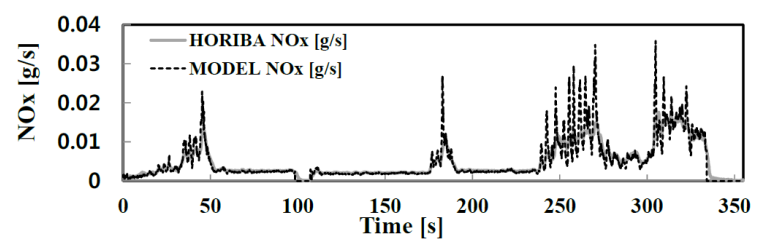

(d)

Figure7. The validation results of NO and NOx estimation of the model during ECE-15 and EUDC cycle. (a) NO validation on ECE-15 cycle; (b) NO validation on EUDC cycle; (c) NOx validation on ECE-15 cycle; (d) NOx validation on EUDC cycle.

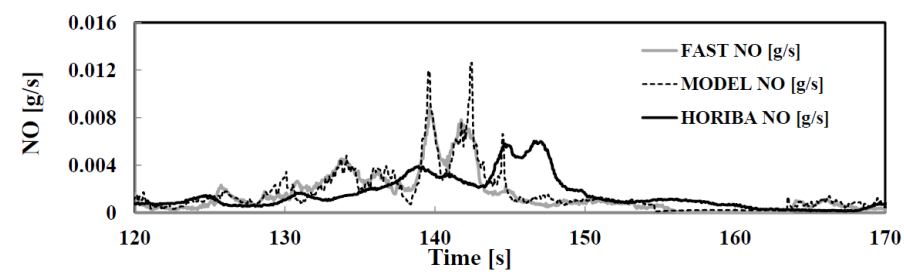

Figure 8. The comparison of measurement characteristics between fast NO analyzer and exhaust gas analyzer during part of the ECE-15 cycle. 
For a quantitative analysis of the results, a 5-second average value was obtained using the raw data. The left side of Figure 9 shows the 5-second average profiles of the predicted and measured NO and NOx. The measurement delay of the exhaust gas analyzer is corrected. The right side describes the degree of matching of the model and measurement using the 5-second window. It can be observed that the model predicts the NO and NOx emission during the emission cycles well with a high $\mathrm{R} 2$ values.

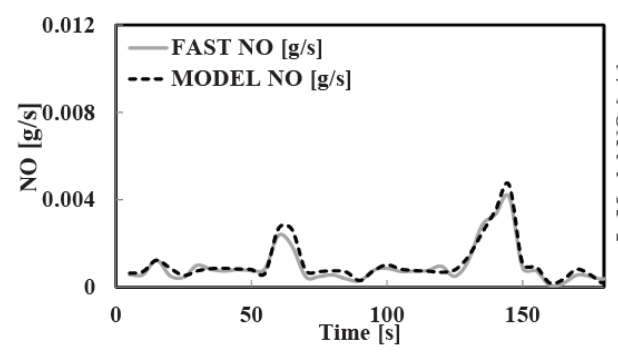

(a)
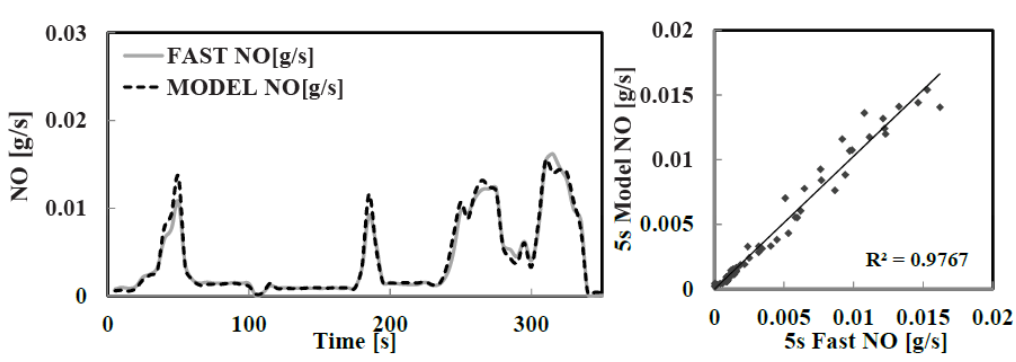

(b)
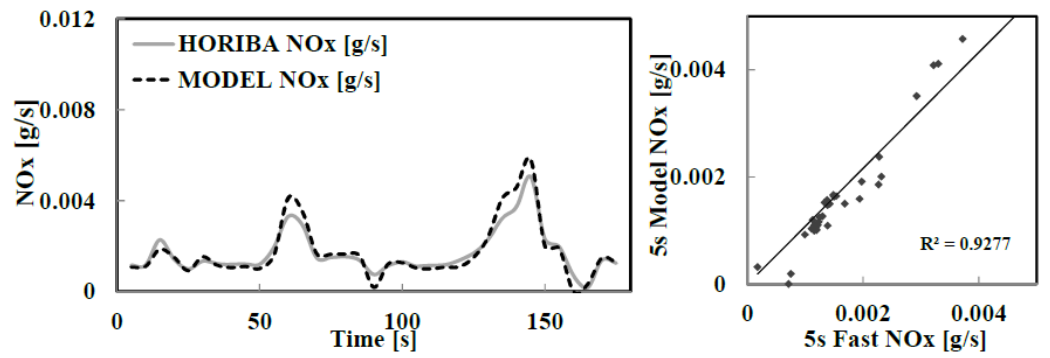

(c)
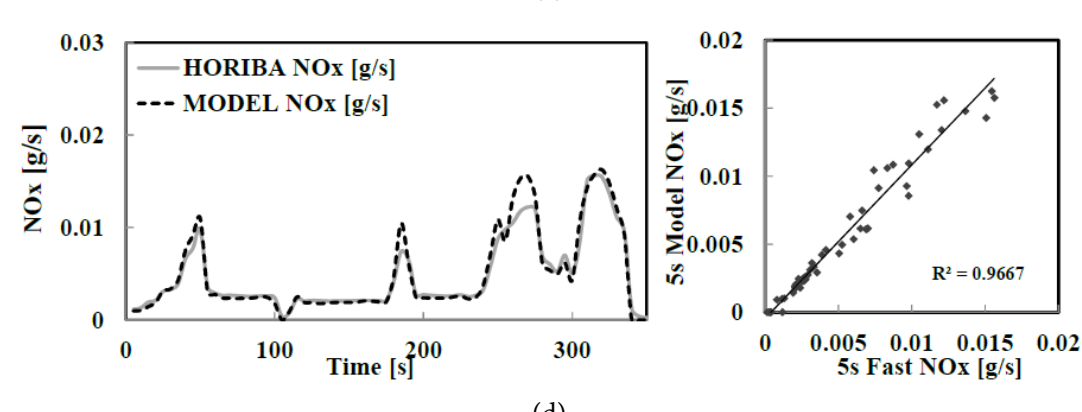

(d)

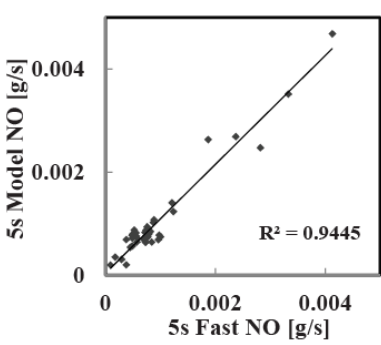

Figure 9. The validation results of $5 \mathrm{~s}$ average $\mathrm{NO}$ and NOx estimation of the model on ECE-15 and EUDC cycle (Table 1). (a) 5 s average NO validation on ECE-15 cycle; (b) $5 \mathrm{~s}$ average NO validation on EUDC cycle; (c) 5 s average NOx validation on ECE-15 cycle; (d) 5 s average NOx validation on EUDC cycle. 
Table 1. ECE-15 and EUDC cycle results.

\begin{tabular}{cccc}
\hline$[\mathrm{g} / \mathrm{km}]$ & Horiba & Fast NO & Model \\
\hline ECE-15 (NO) & 0.052 & 0.048 & 0.051 \\
ECE-15 ((NOx) & $0 / 075$ & $\mathrm{x}$ & 0.073 \\
EUDC (NO) & 0.211 & 0.206 & 0.195 \\
EUDC (NOx) & 0.247 & $\mathrm{x}$ & 0.239 \\
\hline
\end{tabular}

\section{Conclusion}

It can be concluded that the presented model can reliably estimate engine-out NOx. Therefore, this model can be applied to an engine as a good tool forcont rolling engine-out NO and after treatment systems without the need for the NOx sensor. Moreover, the estimation model can be applied to 1-D simulations, such as GT-SUITE and AMESIM, and it shows improved NOx estimation results than that of their own NOx model as the model is able to predict the NO level as same standard as the 3-D CFD simulation.

\section{References}

[1] Sanjay, M.C. (1993) A Review of NOx Formation under Gas-Turbine Combustion Conditions. Combustion Science and Technology, 87, 329-362. https://doi.org/10.1080/00102209208947221

[2] Pacher, P., Beckman, J.S. and Liaudet, L. (2007) Nitric Oxide and Peroxynitrite in Health and Disease. Physiological Reviews, 87, 315-424.

https://doi.org/10.1152/physrev.00029.2006 